\title{
Article
}

\section{Cost-Effective Fabrication of Fractal Silicon Nanowire Arrays}

\author{
Antonio Alessio Leonardi ${ }^{1,2,3}$, Maria José Lo Faro ${ }^{1,3}{ }^{\circledR}$, Maria Miritello ${ }^{3}$, Paolo Musumeci ${ }^{1}$, Francesco Priolo ${ }^{1}$, \\ Barbara Fazio $^{2, *}$ and Alessia Irrera ${ }^{2, *}$ (i) \\ 1 Dipartimento di Fisica e Astronomia "Ettore Majorana", Università di Catania, Via Santa Sofia 64, \\ 95123 Catania, Italy; antonio.leonardi@dfa.unict.it (A.A.L.); mariajose.lofaro@dfa.unict.it (M.J.L.F.); \\ Paolo.musumeci@ct.infn.it (P.M.); francesco.priolo@ct.infn.it (F.P.) \\ 2 CNR-IPCF, Istituto per i Processi Chimico-Fisici, Viale F. Stagno D'Alcontres 37, 98158 Messina, Italy \\ 3 CNR-IMM UoS Catania, Istituto per la Microelettronica e Microsistemi, Via Santa Sofia 64, \\ 95025 Catania, Italy; maria.miritello@infn.ct.it \\ * Correspondence: barbara.fazio@cnr.it (B.F.); irreraalessia@gmail.com (A.I.); Tel.: +39-0903-9762-266 (A.I.)
}

Citation: Leonardi, A.A.; Lo Faro, M.J.; Miritello, M.; Musumeci, P.;

Priolo, F.; Fazio, B.; Irrera, A.

Cost-Effective Fabrication of Fractal Silicon Nanowire Arrays.

Nanomaterials 2021, 11, 1972. https://

doi.org/10.3390/nano11081972

Academic Editors: Vladimir

G. Dubrovskii and Karthik Shankar

Received: 27 May 2021

Accepted: 29 July 2021

Published: 31 July 2021

Publisher's Note: MDPI stays neutral with regard to jurisdictional claims in published maps and institutional affiliations.

\section{Copyright: (C) 2021 by the authors.} Licensee MDPI, Basel, Switzerland. This article is an open access article distributed under the terms and conditions of the Creative Commons Attribution (CC BY) license (https:// creativecommons.org/licenses/by/ $4.0 /)$.

\begin{abstract}
Silicon nanowires (Si NWs) emerged in several application fields as a strategic element to surpass the bulk limits with a flat compatible architecture. The approaches used for the Si NW realization have a crucial impact on their final performances and their final cost. This makes the research on a novel and flexible approach for Si NW fabrication a crucial point for Si NW-based devices. In this work, the novelty is the study of the flexibility of thin film metal-assisted chemical etching (MACE) for the fabrication of Si NWs with the possibility of realizing different doped Si NWs, and even a longitudinal heterojunction p-n inside the same single wire. This point has never been reported by using thin metal film MACE. In particular, we will show how this approach permits one to obtain a high density of vertically aligned Si NWs with the same doping of the substrate and without any particular constraint on doping type and level. Fractal arrays of Si NWs can be fabricated without any type of mask thanks to the self-assembly of gold at percolative conditions. This Si NW fractal array can be used as a substrate to realize controllable artificial fractals, integrating other interesting elements with a cost-effective microelectronics compatible approach.
\end{abstract}

Keywords: silicon nanowires; MACE metal-assisted chemical etching; fractal; photonics; erbium

\section{Introduction}

Silicon nanowires (Si NWs) are emerging as a promising resource in different fields such as electronics [1-5], photovoltaics [6-10], and recently, photonics [11-16] and sensing [17-21]. Indeed, 1D nanostructures couple the nanomaterials' advantages with a fabrication compatible with the typical flat architectures of the silicon industry. The approaches used for Si NW realization have a crucial impact on the final performances in all these application fields and determine the final device cost [22]. This makes the research on a novel and flexible approach that can push the Si NW performance a crucial point for Si NW-based devices. Some of the most used approaches are Vapor-Liquid-Solid (VLS) and Deep Reactive Ion Etching (DRIE). However, both of them present several issues that can detrimentally affect the performance and cost of Si NWs.

By using VLS, it is very complex to obtain highly oriented NWs with diameters under tens of nanometers, and, due to this this limitation, disordered bunches of nanowires are commonly synthesized $[23,24]$. The need for high process temperatures is another strong drawback that causes the occurrence of metal contamination and doping disuniformity (when doping is carried out during the growth). DRIE is an anisotropic dry etching that requires a masking procedure. Whereas Electron Beam Lithography (EBL) is not suitable for large-scale production, in recent years, other lithography strategies have emerged. An example is nanoimprinting lithography (NIL) that shows similar EBL features but couples large-scalable fabrication. However, the high cost, the need for expensive dedicated 
equipment, and the limit of 50:1 (in some state-of-the-art cases, up to 100:1) on the aspect ratio affect this approach for the realization of ultrathin NWs.

All these issues characterize the demand for novel flexible fabrication methods that can allow a cost-effective realization of high-quality Si NWs with great control on doping and in-plane geometry. In recent years, metal-assisted chemical etching (MACE) arose as an innovative anisotropic wet etching method able to promote a cost-effective, largescalable, and microelectronics-compatible fabrication $[22,25,26]$. In this approach, highly electronegative metals are used to catalyze and drive the Si etching at room temperature. While masked approaches on the metal structure permit one to achieve a high control on the Si structure geometry, the mask resolution limits the diameter that can be obtained, thus making the fabrication of quantum confined Si NWs very complicated. Moreover, all these approaches add another commonly complex and expensive step to the synthesis. Different authors [27-30] demonstrate the application of maskless metal film MACE. An alternative route to ordered material that found interesting applications in several fields is represented by disordered nanostructures, by a far less expensive and easy-to-fabricate design.

Moreover, different textural disorder approaches are emerging in novel materials made up of arrays of nanostructures, such as fractal disorder. This is due to a variety of remarkable phenomena that can arise in these media such as superconductivity, superdiffusivity, and non-linear optics. Moreover, fractals have interesting applications in photonics. Indeed, their ability to promote strong multiple scattering and trap light in a wide wavelength range is potentially useful in developing next-generation optical devices [14]. In the photovoltaics field, this occurrence becomes of crucial interest to reduce the cost of the produced energy [6]. All these aspects have driven the realization of a 2D random fractal of Si NWs with the extreme advantage of being compatible with the current $\mathrm{Si}$ industry $[14,31]$.

Our group has demonstrated the realization of a 2D random fractal array of $\mathrm{Si}$ NWs by using a fractal thin metal film of a few nanometers of Au as a catalyst. In two-step MACE, the Si NW array is obtained as the negative mask of the starting discontinuous metal film. In particular, the metal acts as a catalyst driving the silicon etching underneath the film, while the uncovered silicon is unetched and will form the Si NWs. Hence, the engineering of the Au film can be an interesting strategy to texture the Si NW array. In the literature, it is well known that a percolative gold layer is a $2 \mathrm{D}$ random fractal [32]. A percolative gold layer is characterized by the appearance (or disappearance) of connected regions of an infinite extent that permit the constant identification of a path connecting the edges of the considered area [33]. The percolation threshold is directly correlated to a fractal geometry of the system and it is well known that by using a percolative gold layer deposition, it is possible to obtain a fractal $\mathrm{Au}$ film. By the self-assembly of a thin gold layer in percolative conditions, this method permits one to obtain both room temperature light-emitting $\mathrm{Si}$ NWs and fractal in-plane geometry $[14,31]$. Contrary to most of the literature reporting NWs with a diameter of several tens of nanometers, our approach permits the fabrication of sub-10 nm thick NWs and a huge density of $10^{12} \mathrm{NWs} / \mathrm{cm}^{2}$. The use of the self-assembly of gold is a cost-effective solution for a controllable morphology that does not imply the use of any masking approach. Indeed, in our case, no masking procedures are applied, and the NW geometry is determined by the negative development of the percolative gold layer. In our work, we demonstrate that the interesting characteristics of a cost-effective, fast, industrially compatible, and flexible synthesis of MACE can be coupled with a quantum confinement suitable dimension and fractal array organization by our synthesis.

The interest in 2D artificial random fractal Si NWs has driven our research through new methods to fabricate controllable artificial fractals based on our Si NWs integrated with other interesting materials. Among all the elements that can be coupled with $\mathrm{Si}$, the integration of different light-emitting materials represents an interesting opportunity for silicon photonics $[13,34,35]$. In particular, erbium has a special role as one of the most studied and interesting elements that is compatible with standard silicon technology [36-38]. However, Er is characterized by low solubility and low excitation cross-section in a silicon 
substrate [39-42], and an interesting strategy to overcome these issues involves the use of erbium silicates. In these materials, erbium is not a dopant but a constituent [43]. Among them, yttrium oxide $\left(\mathrm{Y}_{2} \mathrm{O}_{3}\right)$ is a Si-compatible material [44] that arises as a strategic solution to minimize the ion-ion interactions [45] that may suppress the Er light emission. Indeed, $\mathrm{Y}_{2} \mathrm{O}_{3}$ and $\mathrm{Er}_{2} \mathrm{O}_{3}$ crystalline structures are very similar and $\mathrm{Er}$ atoms can be introduced in the $\mathrm{Y}$ substitutional position. In our approach, we demonstrated the possibility to integrate $\mathrm{Er}$ in an industrially compatible way in Si NW arrays without any damaging process and without the need for further post-processing approaches. Moreover, this proposed glancing angle decoration process, coupled with the fractal Si NW structure, permits one to control the optical properties by simply varying the deposition angle [14]. In contrast to ionic implantation, where it is necessary to change the implant dose, in our case, this does not introduce any further defects and further processes, such as annealing, are not required.

In this paper, we report for the first time the thin film MACE synthesis of Si NWs with different doping and with the possibility of realizing longitudinal p-n heterojunction inside the same wire. This point, coupled with the extreme flexibility of our approach to the realization of $\mathrm{Si}$ NWs, has never been reported. A comprehensive overview of the main properties of $\mathrm{Si}$ NWs realized by thin-film MACE is presented. In particular, an important novelty is the study and characterization of the NW length and etching velocity of the thin film MACE as a function of the doping level, thus highlighting how this approach allows one to obtain NWs of different doping types and levels, even permitting the growth of p-n-doped Si NWs during the same etching procedure. Concerning the texture and in-plane geometry, it is shown how, without any expensive mask, this approach can be carried out for the realization of 2D random fractal arrays. These 2D fractal Si NWs can be used as substrates in a glancing angle sputtering deposition for the realization of controllable artificial fractal arrays in silicon and with a cost-effective microelectronicscompatible approach that can integrate other interesting elements. As an example of that, we report the decoration of fractal $\mathrm{Si} W$ s with $\mathrm{Er}_{\mathrm{Y}} \mathrm{Y}_{2} \mathrm{O}_{3}$. The angle at which the deposition is performed can be used to vary and control the final fractal morphology, showing an interesting perspective for disorder engineering in a silicon platform.

\section{Materials and Methods}

\subsection{Materials and Chemicals}

Hydrofluoric acid was bought from Honeywell, while hydrogen peroxide was purchased from Sigma Aldrich (Merck KGaA Headquarters of the Merck Group, Frankfurter Strasse 250, Darmstadt, Germany). High-purity (99.9\%) gold pellets as the Au source for electron beam evaporation and the aluminum zinc oxide (AZO) target for sputtering deposition were acquired from Kurt J. Lesker (Kurt J. Lesker Company 1925 Route 51 Jefferson Hills, PA 15025 USA). Si NWs were synthesized starting from a 4" (100)-oriented Si wafer acquired from Siegert Wafer (SIEGERT WAFER GmbH, Charlottenburger Allee 7, Aachen, Germany).

\subsection{Thin Film Metal-Assisted Chemical Etching and AZO Deposition}

Si NWs were fabricated by the thin film metal-assisted chemical etching (MACE). This method involves anisotropic wet etching catalyzed by a discontinuous few-nanometer metal film. Firstly, the Si wafers with different doping types were cleaned and the native silicon oxide was removed by HF etching with a $2.5 \mathrm{M}$ hydrofluoric acid aqueous solution. The samples were then inserted inside the high vacuum chamber of an electron beam evaporator and a $2 \mathrm{~nm}$ thick discontinuous gold film was deposited at room temperature and in a high vacuum condition $\left(<10^{-6} \mathrm{mbar}\right)$. After the deposition, the samples were immersed in an etching solution of $5 \mathrm{M} \mathrm{HF}$ and $0.44 \mathrm{M} \mathrm{H}_{2} \mathrm{O}_{2}$. The gold acted as a catalyst, inducing the local oxidation (favored by the $\mathrm{H}_{2} \mathrm{O}_{2}$ ) of the silicon in contact with the metal. The $\mathrm{SiO}_{2}$ formed underneath the gold was then dissolved due to the presence of the HF. As a consequence, the $\mathrm{Si}$ was anisotropically etched just underneath the gold and formed 
the NWs in the uncovered regions. Finally, Au was removed by a gold etching solution and, since all the processes were at room temperature, no gold contamination occured.

\subsection{Characterization Equipment and Measurement Details}

Scanning Electron Microscope (SEM) images were acquired by a ZEISS SUPRA 25 (Carl-Zeiss-Straße 22, Oberkochen, Germany). The fracLac plugin of ImageJ analysis software through the non-overlapping box-counting algorithm was used to measure the fractal parameters of fractal dimension and lacunarity. The algorithm was implemented on plan-view SEM images acquired at a magnification of $50 \mathrm{kX}$ and $100 \mathrm{kX}$. During the approach, the images were sectioned in a grid of variable dimensions measuring the pixel density statistic (average value and standard deviation) for each box dimension to calculate both fractal dimension and lacunarity.

The Er: $\mathrm{Y}_{2} \mathrm{O}_{3}$ film thickness was measured by both SEM analysis and Rutherford backscattering spectrometry (RBS) on the Si bulk reference substrates. RBS analyses were also carried out to measure the elemental composition of Er: $\mathrm{Y}_{2} \mathrm{O}_{3}$-decorated $\mathrm{Si}$ and $\mathrm{Si}$ NWs. In all the RBS experiments, a $\mathrm{He}^{+}$beam at an energy of $2 \mathrm{MeV}$ impinged onto the samples and the backscattered $\mathrm{He}^{+}$ions were collected at the detection angle of $165^{\circ}$ with respect to the beam direction. The energy loss of the backscattered ions was measured by a multichannel analyzer. Er silicates' presence was investigated by X-ray diffraction (XRD) measurements performed onto Si bulk and Si NWs by using a Bruker X-Ray Diffractometer.

\section{Results and Discussion}

Si NWs were synthesized according to the thin film MACE process as described in the Materials and Methods section. A $2 \mathrm{~nm}$ discontinuous Au layer was deposited on a Si substrate by electron beam evaporation. Subsequently, the sample was immersed in an aqueous solution of hydrofluoric acid and hydrogen peroxide. The Si etching was driven by the gold film and the Si was unetched in the uncovered Si regions where Si NWs were realized.

In Figure 1a,b, the cross-section Scanning Electron Microscope (SEM) images of two Si NW samples obtained starting from two n-doped substrates with As concentrations of about $1.6 \times 10^{16} \mathrm{~cm}^{-3}$ (resistivity $1-5 \mathrm{Ohm} \times \mathrm{cm}$ ) and $1.6 \times 10^{19} \mathrm{~cm}^{-3}$ (resistivity $0.005 \mathrm{Ohm} \times \mathrm{cm}$ ), are, respectively, reported. Indeed, by this synthesis method, the $\mathrm{Si}$ NW doping is the same as the starting Si substrate, and by changing the substrate doping, it is possible to obtain different doped NWs. This approach is extremely flexible and, when using a p-n-doped Si substrate, it is even possible to obtain simultaneously p-ndoped Si NWs. Starting from a Si substrate with an about $800 \mathrm{~nm}$ p-doped (B atoms $1 \times 10^{17} \mathrm{~cm}^{-3}$, resistivity $0.5 \mathrm{Ohm} \times \mathrm{cm}$ ) layer on the remaining heavily n-doped (As atoms $1.6 \times 10^{19} \mathrm{~cm}^{-3}$, resistivity $0.005 \mathrm{Ohm} \times \mathrm{cm}$ ) bulk, we obtained Si NWs with a p-doped region in the first $800 \mathrm{~nm}$ of layer thickness and an n-doped one in the remaining $1400 \mathrm{~nm}$ (as reported in Figure 1c). As sketched in Figure 1c, this approach permits us to realize large-scale high-density Si NWs with a p-n junction inside each NW. All the reported Si NWs are about $2.2 \mu \mathrm{m}$ long and with a huge Si NW density of about $10^{12} \mathrm{NWs} / \mathrm{cm}^{2}$ [22], a crucial point for all the applications. 


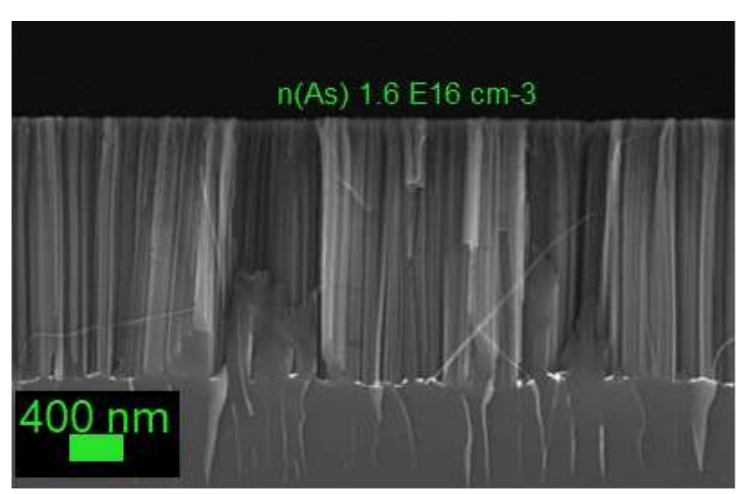

a

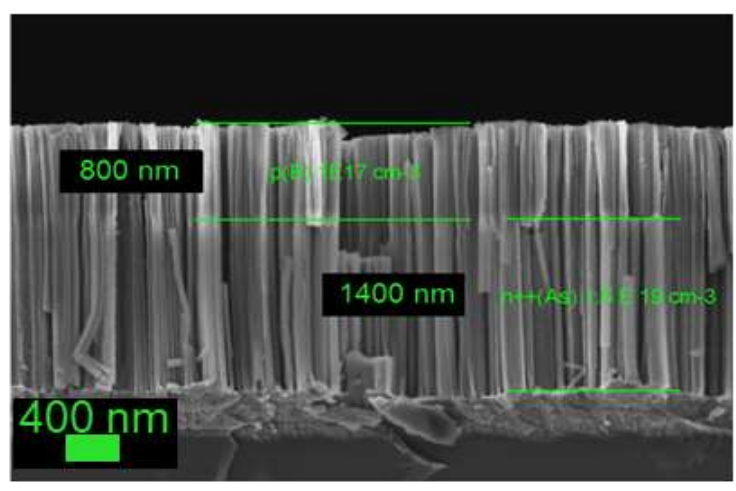

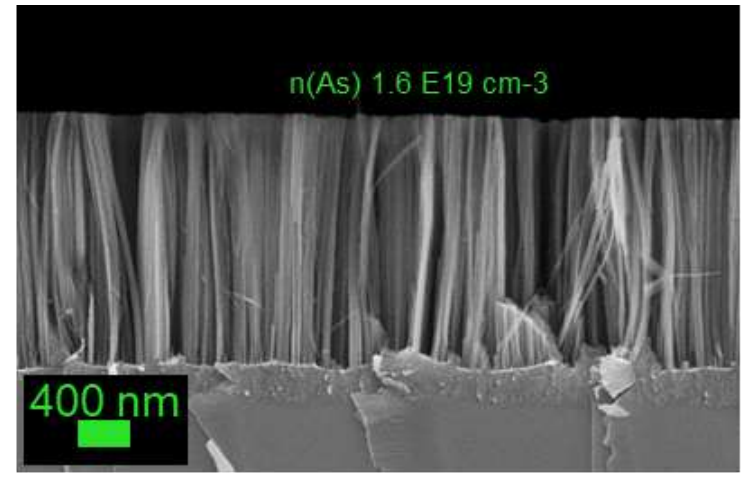

b

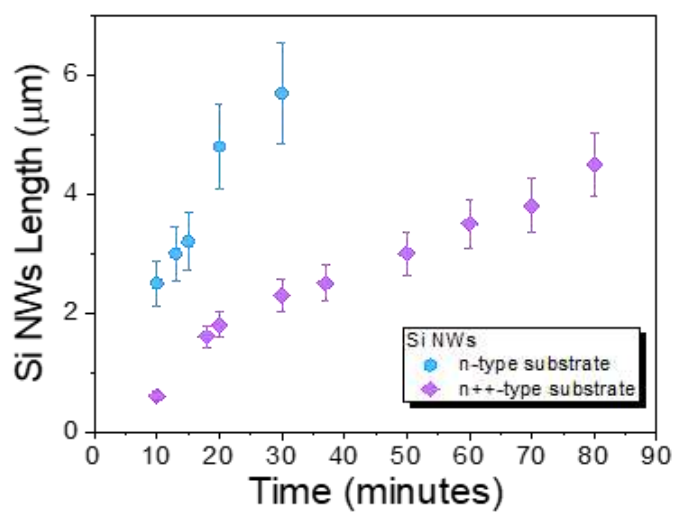

d

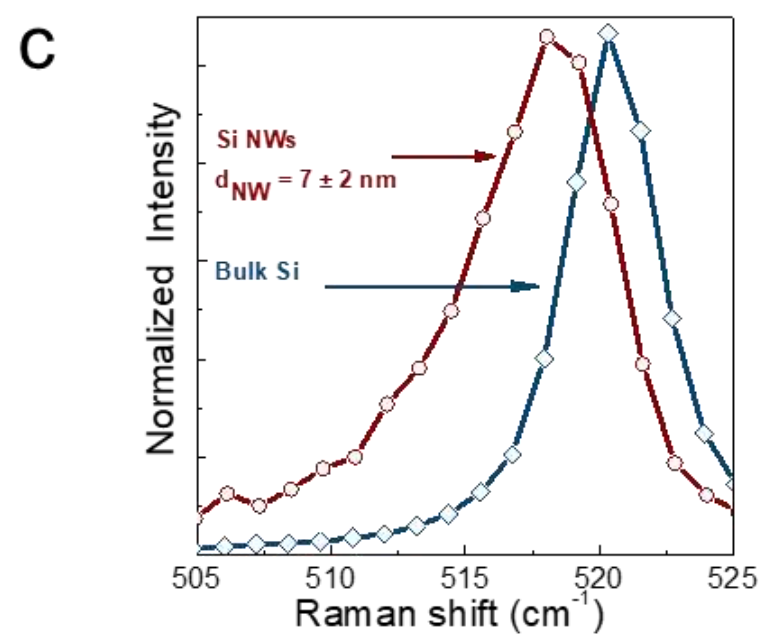

e

Figure 1. Cross-section SEM images of Si NWs realized starting from lightly n-doped (As atoms $1.6 \times 10^{16} \mathrm{~cm}^{-3}$, resistivity $5 \mathrm{Ohm} \times \mathrm{cm}$ ), heavily n-doped (As atoms $1.6 \times 10^{19} \mathrm{~cm}^{-3}$, resistivity $0.005 \mathrm{Ohm} \times \mathrm{cm}$ ), and p-n $\left(\mathrm{B}\right.$ atoms $1 \times 10^{17} \mathrm{~cm}^{-3}$, resistivity $0.5 \mathrm{Ohm} \times \mathrm{cm}$ and As atoms $1.6 \times 10^{19} \mathrm{~cm}^{-3}$, resistivity $0.005 \mathrm{Ohm} \times \mathrm{cm}$ ) substrates in (a-c) respectively. (d) Si NW length as a function of the etching time for lightly doped (indicated as n-type) and heavily doped n-type (indicated as n++-type) substrates (e).

By changing the etching time, it is possible to vary the Si NW length by using (100)-orientated wafers in the case of n-type doping, as shown in Figure 1d. In particular, the length of the obtained Si NW lightly n-doped (As atoms $1.6 \times 10^{16} \mathrm{~cm}^{-3}$, resistivity $1-5 \mathrm{Ohm} \times \mathrm{cm}$ ) and heavily n-doped (As atoms $1.6 \times 10^{19} \mathrm{~cm}^{-3}$, resistivity $0.005 \mathrm{Ohm} \times \mathrm{cm}$ ) are reported as a function of the etching time in cyan and pink, re- 
spectively. In standard MACE processes, the etching velocity strongly depends on the doping type and level [46], and in our fabrication approach, we found this etching velocity to be very similar for lightly doped $\mathrm{p}$ and $\mathrm{n}$ NWs [11]. Indeed, the etching process occurs following the $\mathrm{Si}$ oxidation that is driven by the hole injection catalyzed by the metal. In particular, the hole injection depends on the redox potentials of the etch solution (catalyzed by the metal) and on the Fermi level $E_{f}$ of the semiconductor [47-49] that is determined by the doping. In particular, here, we show that as the doping level increases from the slightly doped substrate to the heavy one, there is a decrease factor of 2.5 in the etching ratio (expressed as length/time).

Raman spectroscopy is a very diffused and investigated approach for the study of Si-based nanostructures [50], able to provide interesting information. In Figure 1e, the first-order Stokes Raman signal of the Si NWs and of Si bulk is shown in red and blue, respectively. The Si NWs signal is characterized by an asymmetrically broadened peak red, shifted with respect to the symmetric and sharper signal typical of bulk crystalline $\mathrm{Si}$, which is found at $520 \mathrm{~cm}^{-1}$. The shift and the asymmetrical shape are in agreement with the literature concerning quantum confined crystalline Si nanostructures. Indeed, this peak can be fitted by the Campbell and Fauchet [51-53] phenomenological method to obtain a $\mathrm{NW}$ diameter value of $7 \pm 2 \mathrm{~nm}$ for the $2 \mathrm{~nm}$ thick Au film.

The main structural parameters of these fabricated Si NWs are reported in Table 1 compared to the literature.

Table 1. Comparison between Si NWs in this work and literature.

\begin{tabular}{|c|c|c|c|c|c|c|c|}
\hline $\begin{array}{l}\text { Length } \\
(\mu \mathrm{m})\end{array}$ & $\begin{array}{l}\text { Average } \\
\text { Diameter } \\
(\mathrm{nm})\end{array}$ & $\begin{array}{l}\text { Density } \\
\left(\mathrm{NW} / \mathrm{cm}^{2}\right)\end{array}$ & $\begin{array}{l}\text { Fab. Time } \\
\quad(\min )\end{array}$ & Doping & Other Char. & Method & Ref. \\
\hline $2-3$ & $5-10$ & $10^{12}$ & $10-50$ & $\begin{array}{c}\text { n++-,n-type, } \\
\text { p-n++ } \\
\text { junction }\end{array}$ & $\begin{array}{l}\text { Fractal arrays and } \\
\text { quantum confined }\end{array}$ & $\begin{array}{l}2 \mathrm{~nm} \mathrm{Au} \\
\mathrm{MACE}\end{array}$ & $\begin{array}{l}\text { This } \\
\text { work }\end{array}$ \\
\hline $2-3$ & $\geq 39$ & $10^{8}$ & / & Undoped & $\begin{array}{l}\text { Si NWs inside } \\
\text { microchannel } \\
\text { structures }\end{array}$ & VLS & [23] \\
\hline $1.5-3$ & $40-50$ & / & $6-8$ & / & $\begin{array}{l}\text { RIE coupled with } \\
\text { nanoimprinting } \\
\text { lithography }\end{array}$ & Deep RIE & [54] \\
\hline $5-20$ & 70-100 & / & $20-60$ & p-type & $\begin{array}{l}\text { Metal patterned area } \\
\text { by UV lithography }\end{array}$ & $\begin{array}{l}\text { Silver salt } \\
\text { MACE }\end{array}$ & [55] \\
\hline $1.5-6$ & $20-300$ & / & $6-10$ & n-type & $\begin{array}{c}\text { Metal patterned area } \\
\text { by Colloidal } \\
\text { templates }\end{array}$ & $\begin{array}{l}\text { Au/Ti thin film } \\
\text { MACE }\end{array}$ & {$[30]$} \\
\hline $1.5-2$ & $60-120$ & $10^{8}-10^{9}$ & $5-10$ & n-type & $\begin{array}{l}\text { Si NWs size further } \\
\text { reduced by } \mathrm{KOH} \\
\text { etching with tailored } \\
\text { shape design }\end{array}$ & Au film MACE & [56] \\
\hline Up to 100 & $200-3000$ & / & 60-180 & p-, n-type & Microstructurres & $\begin{array}{l}\mathrm{Ag} / \mathrm{Au} \text { film } \\
\text { Mace }\end{array}$ & [57] \\
\hline $2-3$ & $500-100$ & $10^{7}-10^{8}$ & 20 & p-type & $\begin{array}{c}\text { Tailored shape } \mathrm{Si} \\
\text { wires }\end{array}$ & $\begin{array}{l}\mathrm{Au} / \mathrm{Ti} \text { thin film } \\
\text { MACE }\end{array}$ & [58] \\
\hline $0.2-10$ & 55 & $10^{8}-10^{9}$ & $0.5-4$ & n-type & $\begin{array}{c}\text { Metal patterned area } \\
\text { by nanosphere } \\
\text { lithography }\end{array}$ & $\begin{array}{l}\text { Au thin film } \\
\text { MACE }\end{array}$ & [59] \\
\hline 1 & $40-60$ & $10^{8}-10^{10}$ & 60 & p-type & $\begin{array}{l}\text { Metal patterned area } \\
\text { by AAO membranes }\end{array}$ & $\begin{array}{l}\text { Au/Ag thin } \\
\text { film MACE }\end{array}$ & [60] \\
\hline
\end{tabular}

Another crucial point, discussed in the Introduction, is that this fabrication method allows the realization of fractal arrays of Si NWs that can be decorated with other materials for the realization of Si-based artificial fractal. In Figure 2, the as-grown fractal Si NW array, as well as the decorated samples with $\mathrm{Er}_{2} \mathrm{Y}_{2} \mathrm{O}_{3}$ at $5^{\circ}, 10^{\circ}$, and $15^{\circ}$, are shown. It is clearly 
visible that the decoration process does not close all the air gaps. This is a crucial point that preserves and engineers the fractal morphology of the system. Indeed, the interstices among Si NWs appear to be more covered for small angles, with a clear variation of the fill factor (FF). The fill factor is the ratio of the covered area per the total area of the analyzed image that we measured by pixel counting with the ImageJ software. An FF of $42 \pm 2 \%$ was measured for the bare Si NWs sample, while an FF of $76 \pm 1 \%, 74 \pm 1 \%$, and $69 \pm 1 \%$ for Er: $\mathrm{Y}_{2} \mathrm{O}_{3}$-decorated $\mathrm{Si} \mathrm{NWs}$ at $5^{\circ}, 10^{\circ}$, and $15^{\circ}$ angles were obtained. The higher the angle, the smaller the measured FF, with a decrease in the in-plan coverage. This effect can be understood considering that higher deposition angles correspond to the smaller aperture angle of the shadowing cone. Therefore, by varying the oblique angle used in the sputtering process, we can tune the fractal morphology of the decorated samples. Indeed, the fractal key feature is the scale invariance that can be measured as the scale invariance of the FF at different magnifications [14,61]. Both the bare Si NWs and the Er: $\mathrm{Y}_{2} \mathrm{O}_{3}$-decorated Si NWs show a constant fill factor at different magnifications (10-300 kX range).

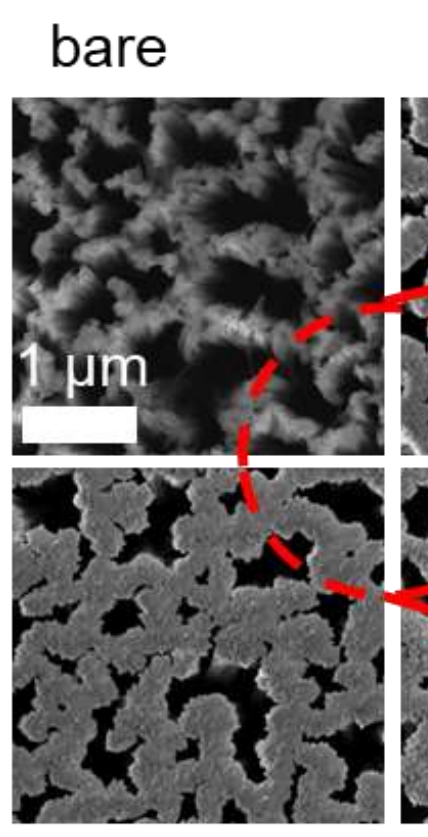

\section{$5^{\circ}$}
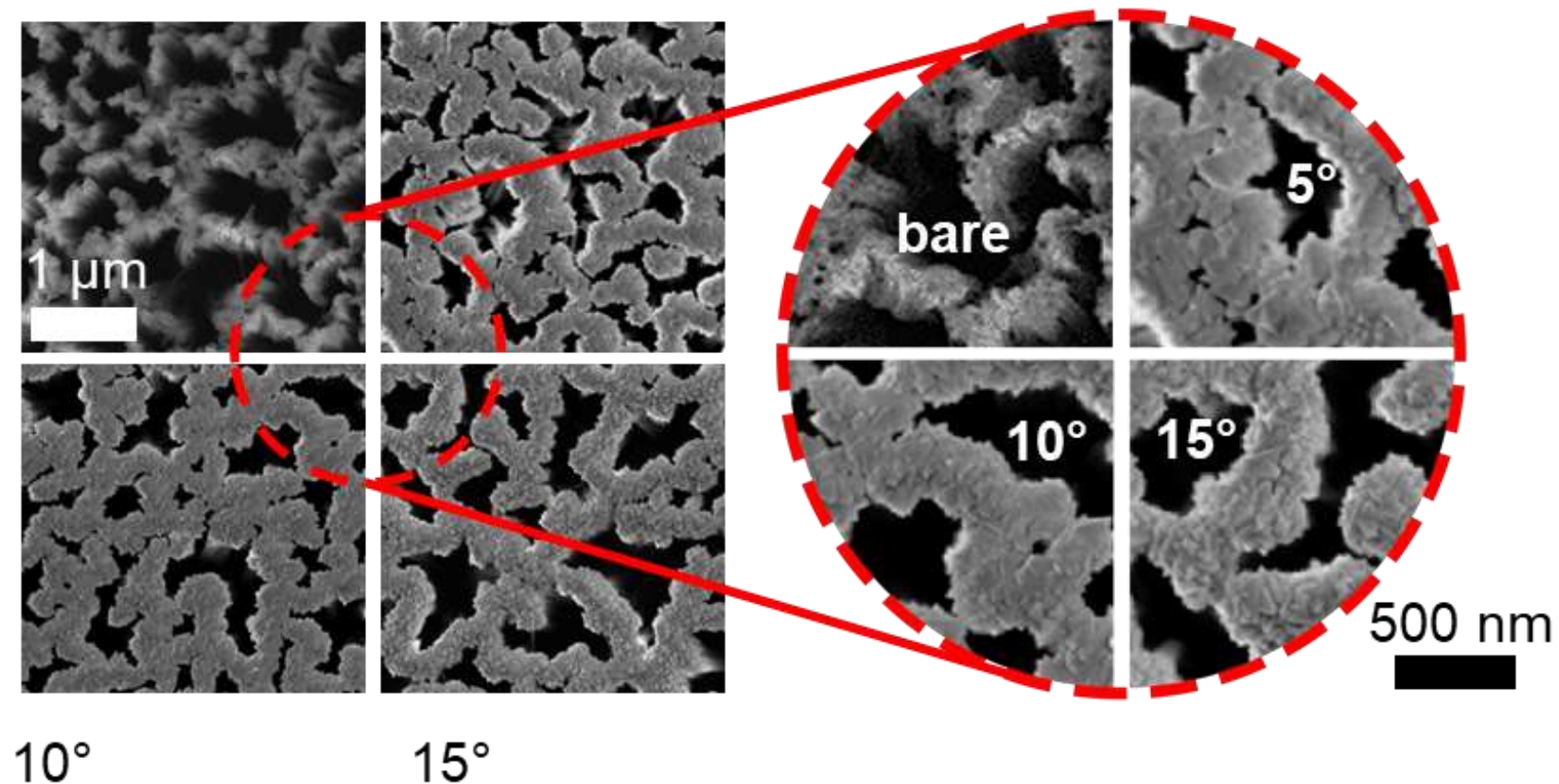

$15^{\circ}$

Figure 2. Plan-view SEM images of fractal bare $\mathrm{Si} N W s, 5^{\circ}, 10^{\circ}$, and $15^{\circ} \mathrm{Er}: \mathrm{Y}_{2} \mathrm{O}_{3}$ decorated at the same magnification are reported on the left side. On the right side, to highlight the different coverage and filling factor, a magnification of all these images is shown.

The fractal nature of the sample was studied by the plugin FracLac sliding box of ImageJ used on the binary converted SEM images. The sliding box algorithm parameters were set as equal for all the samples to guarantee consistency between the results. Both fractal dimension and lacunarity were investigated for each deposition angle. Lacunarity is a parameter introduced by Mandelbrot [62] that takes into account the statistical fluctuation of the mass probed by the box-counting algorithm for each fixed dimension of the boxes. Lacunarity provides complementary information to the fractal dimension, describing how the fractal texture is organized in terms of the heterogeneity of the sample represented by the fluctuation of the distribution of the alternation of empty and filled spaces as a function of the length scale [63]. As it is possible to observe by the magnification of the SEM images in the right part of Figure 2, the deposition angle affected the FF and the heterogeneity of the samples. These cause different lacunarities at different deposition angles. Therefore, with a simple and cost-effective approach, it is possible to realize artificial fractals based on Si NWs where the morphological and structural fractal parameters can be tuned by varying 
the deposition angle. By controlling the mass fluctuation in terms of lacunarity, it is possible to tune the refractive index fluctuation, and this result is interesting for photonics and photovoltaics, opening the possibility of tuning the light-scattering properties of the system.

The stoichiometry of the elemental composition of the Er: $\mathrm{Y}_{2} \mathrm{O}_{3}$-decorated sample was confirmed by means of a Rutherford backscattering spectrometry (RBS) analysis, shown in Figure 3. Fractal Si NWs are characterized by the presence of air gaps of sizes spanning in the $\mathrm{nm}-\mu \mathrm{m}$ range $[64,65]$. In $\mathrm{Er}_{\mathrm{Y}} \mathrm{Y}_{2} \mathrm{O}_{3}$-covered $\mathrm{Si} \mathrm{NWs}$, the air gaps between the wires are reduced but still present at all the length scales (otherwise, there would be no presence of a fractal). This strong discontinuous structure makes the fitting and analytical interpretation of RBS data extremely complex (NW signal in blue in Figure 3a). As it is observed in Si NW samples, the signals of the constitutional elements (such as Si and Y) are strongly influenced by the discontinuity of the substrate. Indeed, a $\mathrm{He}^{+}$ion can be backscattered from the NW tips as well as from the Si substrate (at $2.3 \mu \mathrm{m}$ of difference, considering the NW height). This strong variation in the Si atom position is reflected in the RBS spectrum shape. These critical issues motivate the stoichiometry quantitative analysis on Si bulk (in red in Figure 3a). Indeed, it is expected for the $5^{\circ}, 10^{\circ}$, and $15^{\circ}$ Er: $\mathrm{Y}_{2} \mathrm{O}_{3}$ depositions on Si bulk to obtain the same stoichiometry at the same deposition conditions of the Si NW samples. In Figure 3a, the signal obtained from the Er: $\mathrm{Y}_{2} \mathrm{O}_{3}$ on $\mathrm{Si}$ bulk sample is shown in red ( $10^{\circ}$ deposition). The presence of the $\mathrm{Er}, \mathrm{Y}, \mathrm{Si}$, and $\mathrm{O}$ signals is highlighted in the graph. The position of these peaks and their extension were fitted by the simulation software SIMNRA, which found an Er concentration of $2 \pm 1$ at $\%$ (areal density of about $0.3 \times 10^{17}$ at $/ \mathrm{cm}^{2}$ ), while $\mathrm{Y}$ and $\mathrm{O}$ showed a concentration of about $38 \pm 2$ at $\%$ (areal density of $4.5 \times 10^{17} \mathrm{at} / \mathrm{cm}^{2}$ ) and $60 \pm 5$ at $\%$ (areal density of $7 \times 10^{17} \mathrm{at} / \mathrm{cm}^{2}$ ), respectively. For the Er: $\mathrm{Y}_{2} \mathrm{O}_{3}$-decorated samples (blue spectrum), the $\mathrm{Si}$ signal shows a clear shift towards lower energy loss channels, which is the result of the additional energy loss of the ion probe due to the $\mathrm{Er}_{\mathrm{Y}} \mathrm{Y}_{2} \mathrm{O}_{3}$ concentration onto the surface.

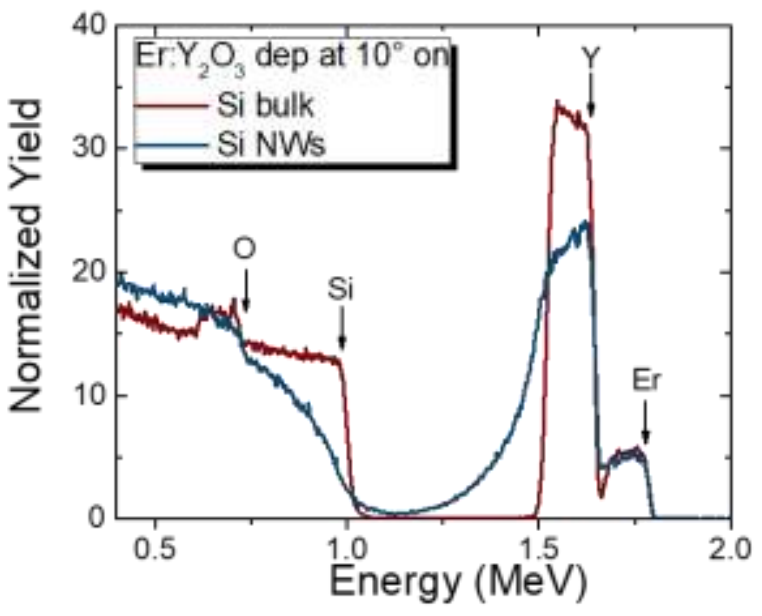

a

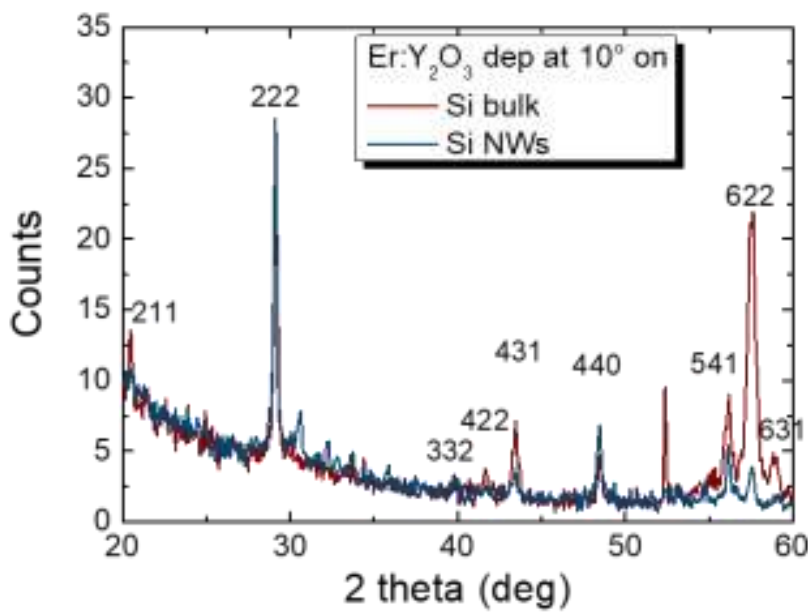

b

Figure 3. (a) Rutherford backscattering spectrometry of the decorated Si bulk (red) and Si NWs (blue) obtained at $10^{\circ}$. (b) X-ray diffraction analysis of the Er: $\mathrm{Y}_{2} \mathrm{O}_{3}$ deposited on Si bulk and Si NWs at $10^{\circ}$.

It is worth noticing that after the Er: $\mathrm{Y}_{2} \mathrm{O}_{3}$ decoration, both the decorated Si bulk and Si NWs attest about the same downshift, suggesting the same concentration of Er, $\mathrm{Y}$, and $\mathrm{O}$ deposited on the two substrates, as expected. This point is strongly confirmed by the same Er and Y integrated peak in the two samples that indicate the presence of the same total amount of material. After the RBS analysis, the Si NWs (in blue) and Si bulk (in red) decorated samples were characterized by XRD with a Bruker X-Ray Diffractometer to demonstrate the absence of Er silicates between Er: $\mathrm{Y}_{2} \mathrm{O} 3$ and Si NWs. It is well known that the presence of Er silicates at the interfaces can strongly detrimentally affect the PL 
emission, acting as non-radiative de-excitation channels. In Figure 3b, the XRD spectra of the Si bulk and Si NWs decorated at $10^{\circ}$ (reported as an example) confirm the good crystalline quality of the Er: $\mathrm{Y}_{2} \mathrm{O}_{3}$ films. The fingerprint of the cubic $\mathrm{Y}_{2} \mathrm{O}_{3}$ crystalline structures is visible for the two samples, and the characteristic $X$-ray diffraction peaks of silicates are not visible, demonstrating their absence. This result is in agreement with the literature, where the formation of Er silicate at the interface between Er: $\mathrm{Y}_{2} \mathrm{O}_{3}$ and Si NWs is absent at a deposition substrate temperature of $300^{\circ} \mathrm{C}$ [66].

\section{Conclusions}

In this paper, the novelty reported is the flexibility of the thin film MACE for the realization of Si NWs and the study of Si NWs characterized by different doping types, and a longitudinal p-n heterojunction inside the same wire. In particular, this approach permits the fabrication NWs in tens of minute, with length up to few microns, without constraints on the doping of the wires that is determined by the starting substrate. Moreover, for the first time, we have demonstrated that by using a wafer with two different doping types, it is even possible to realize p-n NWs with a large-scalable, cost-effective, and microelectronics-compatible approach. To further show the possibility offered by this approach, the fabrication of novel artificial 2D fractal arrays based on Er: $\mathrm{Y}_{2} \mathrm{O}_{3}$-decorated $\mathrm{Si}$ NWs was reported. In particular, the use of glancing angle sputtering was successfully adopted to decorate fractal Si NWs, enabling a fractal morphology control. The Er concentration and the consistency between the different sputtering processes were confirmed through Rutherford backscattering spectrometry, and the absence of silicates was demonstrated by XRD. Thanks to the possibility to control the fractal and lacunarity properties in a glancing angle deposition, this result opens the route to the realization of novel and controllable artificial fractals that integrate interesting elements in a silicon microelectronics-compatible substrate.

Author Contributions: Conceptualization, A.I.; Data curation, A.A.L.; Funding acquisition, A.I.; Investigation, A.A.L., M.J.L.F., M.M., P.M. and B.F.; Methodology, A.A.L. and M.J.L.F.; Resources, F.P. and A.I.; Supervision, A.I. All authors have read and agreed to the published version of the manuscript.

Funding: This research received no external funding.

Data Availability Statement: Data are contained within the article.

Acknowledgments: C. Percolla, G. Lupò, D. Arigò, R. Caruso, and G. Spinella are acknowledged for their expert technical assistance. We acknowledge ADAS + ARS01_00459.

Conflicts of Interest: The authors declare no conflict of interest.

\section{References}

1. Cui, Y.; Zhong, Z.; Wang, D.; Wang, W.U.; Lieber, C.M. High performance silicon nanowire field effect transistors. Nano Lett. 2003, 3, 149-152. [CrossRef]

2. Goldberger, J.; Hochbaum, A.I.; Fan, R.; Yang, P. Silicon vertically integrated nanowire field effect transistors. Nano Lett. 2006, 6, 973-977. [CrossRef]

3. Feng, W.; Hettiarachchi, R.; Sato, S.; Kakushima, K.; Niwa, M.; Iwai, H.; Yamada, K.; Ohmori, K. Advantages of silicon nanowire metal-oxide-semiconductor field-effect transistors over planar ones in noise properties. Jpn. J. Appl. Phys. 2012, 51, 04 DC06. [CrossRef]

4. Javey, A.; Nam, S.; Friedman, R.S.; Yan, H.; Lieber, C.M. Layer-by-layer assembly of nanowires for three-dimensional, multifunctional electronics. Nano Lett. 2007, 7, 773-777. [CrossRef] [PubMed]

5. Schmidt, V.; Riel, H.; Senz, S.; Karg, S.; Riess, W.; Gösele, U. Realization of a Silicon Nanowire Vertical Surround-Gate Field-Effect Transistor. Small 2006, 2, 85-88. [CrossRef] [PubMed]

6. Garnett, E.; Yang, P. Light Trapping in Silicon Nanowire Solar Cells. Nano Lett. 2010, 10, 1082-1087. [CrossRef]

7. Kelzenberg, M.D.; Boettcher, S.W.; Petykiewicz, J.A.; Turner-Evans, D.B.; Putnam, M.C.; Warren, E.L.; Spurgeon, J.M.; Briggs, R.M.; Lewis, N.S.; Atwater, H.A. Enhanced absorption and carrier collection in Si wire arrays for photovoltaic applications. Nat. Mater. 2010, 9, 239-244. [CrossRef] [PubMed]

8. Cao, L.; Fan, P.; Vasudev, A.P.; White, J.S.; Yu, Z.; Cai, W.; Schuller, J.A.; Fan, S.; Brongersma, M.L. Semiconductor Nanowire Optical Antenna Solar Absorbers. Nano Lett. 2010, 10, 439-445. [CrossRef] [PubMed] 
9. Zhang, H.; Lei, Y.; Zhu, Q.; Qing, T.; Zhang, T.; Tian, W.; Lange, M.; Jiang, M.; Han, C.; Li, J.; et al. Nanoscale Photovoltaic Responses in 3D Radial Junction Solar Cells Revealed by High Spatial Resolution Laser Excitation Photoelectric Microscopy. ACS Nano 2019, 13, 10359-10365. [CrossRef]

10. Peters, C.H.; Guichard, A.R.; Hryciw, A.C.; Brongersma, M.L.; McGehee, M.D. Energy transfer in nanowire solar cells with photon-harvesting shells. J. Appl. Phys. 2009, 105, 124509. [CrossRef]

11. Leonardi, A.A.; Faro, M.J.L.; Irrera, A. CMOS-Compatible and Low-Cost Thin Film MACE Approach for Light-Emitting Si NWs Fabrication. Nanomaterials 2020, 10, 966. [CrossRef]

12. Faro, M.J.L.; Leonardi, A.A.; Morganti, D.; Fazio, B.; Vasi, C.; Musumeci, P.; Priolo, F.; Irrera, A. Low Cost Fabrication of Si NWs/CuI Heterostructures. Nanomaterials 2018, 8, 569. [CrossRef]

13. Kalem, S.; Werner, P.; Talalaev, V. Near-IR photoluminescence from Si/Ge nanowire-grown silicon wafers: Effect of HF treatment. Appl. Phys. A Mater. Sci. Process. 2013, 112, 561-567. [CrossRef]

14. Lo Faro, M.J.; Leonardi, A.A.; Priolo, F.; Fazio, B.; Miritello, M.; Irrera, A. Erbium emission in Er: $\mathrm{Y}_{2} \mathrm{O}_{3}$ decorated fractal arrays of silicon nanowires. Sci. Rep. 2020, 10, 12854. [CrossRef] [PubMed]

15. Khorasaninejad, M.; Saini, S.S. Silicon nanowire optical waveguide (SNOW). Opt. Express 2010, 18, 23442-23457. [CrossRef] [PubMed]

16. Khorasaninejad, M.; Saini, S.S. Bend waveguides on silicon nanowire optical waveguide (snow). IEEE Photonics J. 2011, 3, 696-702. [CrossRef]

17. Leonardi, A.A.; Lo Faro, M.J.; Irrera, A. Biosensing platforms based on silicon nanostructures: A critical review. Anal. Chim. Acta 2021, 1160, 338393. [CrossRef]

18. Leonardi, A.A.; Lo Faro, M.J.; Di Franco, C.; Palazzo, G.; D’Andrea, C.; Morganti, D.; Manoli, K.; Musumeci, P.; Fazio, B.; Lanza, M.; et al. Silicon nanowire luminescent sensor for cardiovascular risk in saliva. J. Mater. Sci. Mater. Electron. 2020, $31,10-17$. [CrossRef]

19. Patolsky, F.; Zheng, G.; Lieber, C.M. Nanowire sensors for medicine and the life sciences. Nanomedicine 2006, 1, 51-65. [CrossRef] [PubMed]

20. Engel, Y.; Elnathan, R.; Pevzner, A.; Davidi, G.; Flaxer, E.; Patolsky, F. Supersensitive detection of explosives by silicon nanowire arrays. Angew. Chem. Int. Ed. 2010, 49, 6830-6835. [CrossRef]

21. Tran, D.; Pham, T.; Wolfrum, B.; Offenhäusser, A.; Thierry, B. CMOS-Compatible Silicon Nanowire Field-Effect Transistor Biosensor: Technology Development toward Commercialization. Materials 2018, 11, 785. [CrossRef]

22. Leonardi, A.A.; Lo Faro, M.J.; Irrera, A. Silicon Nanowires Synthesis by Metal-Assisted Chemical Etching: A Review. Nanomaterials 2021, 11, 383. [CrossRef]

23. Hochbaum, A.I.; Fan, R.; He, R.; Yang, P. Controlled growth of Si nanowire arrays for device integration. Nano Lett. 2005, 5, 457-460. [CrossRef] [PubMed]

24. De Boor, J.; Geyer, N.; Wittemann, J.V.; Gösele, U.; Schmidt, V. Sub-100 nm silicon nanowires by laser interference lithography and metal-assisted etching. Nanotechnology 2010, 21, 095302. [CrossRef] [PubMed]

25. Li, L.; Liu, Y.; Zhao, X.; Lin, Z.; Wong, C.P. Uniform vertical trench etching on silicon with high aspect ratio by metal-assisted chemical etching using nanoporous catalysts. ACS Appl. Mater. Interfaces 2014, 6, 575-584. [CrossRef] [PubMed]

26. Lai, R.A.; Hymel, T.M.; Narasimhan, V.K.; Cui, Y. Schottky Barrier Catalysis Mechanism in Metal-Assisted Chemical Etching of Silicon. ACS Appl. Mater. Interfaces 2016, 8, 8875-8879. [CrossRef]

27. Leonardi, A.A.; Nastasi, F.; Morganti, D.; Faro, M.J.L.; Picca, R.A.; Cioffi, N.; Franzò, G.; Serroni, S.; Priolo, F.; Puntoriero, F.; et al. New Hybrid Light Harvesting Antenna Based on Silicon Nanowires and Metal Dendrimers. Adv. Opt. Mater. 2020, 8, 2001070. [CrossRef]

28. Han, H.; Huang, Z.; Lee, W. Metal-assisted chemical etching of silicon and nanotechnology applications. Nano Today 2014, 9 , 271-304. [CrossRef]

29. Wang, S.; Liu, H.; Han, J. Comprehensive study of Au nano-mesh as a catalyst in the fabrication of silicon nanowires arrays by metal-assisted chemical etching. Coatings 2019, 9, 149. [CrossRef]

30. Wendisch, F.J.; Rey, M.; Vogel, N.; Bourret, G.R. Large-Scale Synthesis of Highly Uniform Silicon Nanowire Arrays Using Metal-Assisted Chemical Etching. Chem. Mater. 2020, 32, 9425-9434. [CrossRef]

31. Lo Faro, M.J.; Leonardi, A.A.; D’Andrea, C.; Morganti, D.; Musumeci, P.; Vasi, C.; Priolo, F.; Fazio, B.; Irrera, A. Low cost synthesis of silicon nanowires for photonic applications. J. Mater. Sci. Mater. Electron. 2020, 31, 34-40. [CrossRef]

32. Krachmalnicoff, V.; Castanié, E.; De Wilde, Y.; Carminati, R. Fluctuations of the local density of states probe localized surface plasmons on disordered metal films. Phys. Rev. Lett. 2010, 105, 183901. [CrossRef]

33. Hammersley, J.M. Percolation Processes: Lower Bounds for the Critical Probability on JSTOR. Ann. Math. Stat. 1957, 28, 790-795. [CrossRef]

34. Leong, D.; Harry, M.; Reeson, K.J.; Homewood, K.P. A silicon/iron-disllicide light-emitting diode operating at a wavelength of $1.5 \mu \mathrm{m}$. Nature 1997, 387, 686-688. [CrossRef]

35. Artoni, P.; Pecora, E.F.; Irrera, A.; Priolo, F. Kinetics of si and ge nanowires growth through electron beam evaporation. Nanoscale Res. Lett. 2011, 6, 162. [CrossRef] [PubMed] 
36. Macdougall, S.K.W.; Ivaturi, A.; Marques-Hueso, J.; Krämer, K.W.; Richards, B.S. Broadband photoluminescent quantum yield optimisation of $\mathrm{Er}^{3+}$-doped $\beta-\mathrm{NaYF} 4$ for upconversion in silicon solar cells. Sol. Energy Mater. Sol. Cells 2014, 128, 18-26. [CrossRef]

37. Kim, M.H.; Kim, I.S.; Park, Y.H.; Park, T.E.; Shin, J.H.; Choi, H.J. Platinum assisted vapor-liquid-solid growth of er-si nanowires and their optical properties. Nanoscale Res. Lett. 2010, 5, 286-290. [CrossRef] [PubMed]

38. Kenyon, A.J. Erbium in silicon. Semicond. Sci. Technol. 2005, 20, R65. [CrossRef]

39. Touboltsev, V.; Jalkanen, P.; Räisänen, J.; Smulders, P.J.M. On erbium lattice location in ion implanted $\mathrm{Si}_{0.75} \mathrm{Ge}_{0.25}$ alloy: Computer simulation of Rutherford backscattering/channeling. J. Appl. Phys. 2003, 93, 3668-3670. [CrossRef]

40. Isshiki, H.; Kimura, T. Toward small size waveguide amplifiers based on erbium silicate for silicon photonics. IEICE Trans. Electron. 2008, E91-C, 138-144. [CrossRef]

41. Gao, Y.; Shen, H.; Cao, J.; Li, D.; Yang, D. Control of the formation and luminescent properties of polymorphic erbium silicates on silicon. Opt. Mater. Express 2019, 9, 1716-1727. [CrossRef]

42. Crowe, I.F.; Kashtiban, R.J.; Sherliker, B.; Bangert, U.; Halsall, M.P.; Knights, A.P.; Gwilliam, R.M. Spatially correlated erbium and Si nanocrystals in coimplanted $\mathrm{SiO}_{2}$ after a single high temperature anneal. J. Appl. Phys. 2010, 107, 044316. [CrossRef]

43. Van, T.T.; Bargar, J.R.; Chang, J.P. Er coordination in $\mathrm{Y}_{2} \mathrm{O}_{3}$ thin films studied by extended X-ray absorption fine structure. J. Appl. Phys. 2006, 100, 023115. [CrossRef]

44. Wang, X.; Yan, X.; Kan, C. Controlled synthesis and optical characterization of multifunctional ordered $\mathrm{Y}_{2} \mathrm{O}_{3}: \mathrm{Er}^{3+}$ porous pyramid arrays. J. Mater. Chem. 2011, 21, 4251-4256. [CrossRef]

45. Mao, Y.; Guo, X.; Tran, T.; Wang, K.L.; Shih, C.K.; Chang, J.P. Luminescent properties of ensemble and individual erbium-doped yttrium oxide nanotubes. J. Appl. Phys. 2009, 105, 094329. [CrossRef]

46. Huang, Z.; Shimizu, T.; Senz, S.; Zhang, Z.; Geyer, N.; Gösele, U. Oxidation rate effect on the direction of metal-assisted chemical and electrochemical etching of silicon. J. Phys. Chem. C 2010, 114, 10683-10690. [CrossRef]

47. Backes, A.; Bittner, A.; Leitgeb, M.; Schmid, U. Influence of metallic catalyst and doping level on the metal assisted chemical etching of silicon. Scr. Mater. 2016, 114, 27-30. [CrossRef]

48. Peng, K.; Hu, J.; Yan, Y.; Wu, Y.; Fang, H.; Xu, Y.; Lee, S.; Zhu, J. Fabrication of single-crystalline silicon nanowires by scratching a silicon surface with catalytic metal particles. Adv. Funct. Mater. 2006, 16, 387-394. [CrossRef]

49. Chen, C.Y.; Wu, C.S.; Chou, C.J.; Yen, T.J. Morphological control of single-crystalline silicon nanowire arrays near room temperature. Adv. Mater. 2008, 20, 3811-3815. [CrossRef]

50. Sun, C.Q.; Zhao, H.; Peng, J.Z.; Liu, X.J.; Yang, X.; Liu, Y. Composition- and Temperature-Resolved Raman Shift of Silicon. Appl. Spectrosc. 2018, 72, 598-603.

51. Richter, H.; Wang, Z.P.; Ley, L. The one phonon Raman spectrum in microcrystalline silicon. Solid State Commun. 1981, 39, 625-629. [CrossRef]

52. Campbell, I.H.; Fauchet, P.M. The effects of microcrystal size and shape on the one phonon Raman spectra of crystalline semiconductors. Solid State Commun. 1986, 58, 739-741. [CrossRef]

53. Piscanec, S.; Cantoro, M.; Ferrari, A.C.; Zapien, J.A.; Lifshitz, Y.; Lee, S.T.; Hofmann, S.; Robertson, J. Raman spectroscopy of silicon nanowires. Phys. Rev. B 2003, 68, 241312. [CrossRef]

54. Morton, K.J.; Nieberg, G.; Bai, S.; Chou, S.Y. Wafer-scale patterning of sub-40 nm diameter and high aspect ratio (>50:1) silicon pillar arrays by nanoimprint and etching. Nanotechnology 2008, 19, 345301. [CrossRef]

55. Nassiopoulou, A.G.; Gianneta, V.; Katsogridakis, C. Si nanowires by a single-step metal-assisted chemical etching process on lithographically defined areas: Formation kinetics. Nanoscale Res. Lett. 2011, 6, 597. [CrossRef]

56. Wendisch, F.J.; Abazari, M.; Mahdavi, H.; Rey, M.; Vogel, N.; Musso, M.; Diwald, O.; Bourret, G.R. Morphology-Graded Silicon Nanowire Arrays via Chemical Etching: Engineering Optical Properties at the Nanoscale and Macroscale. ACS Appl. Mater. Interfaces 2020, 12, 13140-13147. [CrossRef]

57. Kim, S.-M.; Khang, D.-Y. Bulk Micromachining of Si by Metal-assisted Chemical Etching. Small 2014, 10, 3761-3766. [CrossRef] [PubMed]

58. Lin, H.; Cheung, H.Y.; Xiu, F.; Wang, F.; Yip, S.; Han, N.; Hung, T.; Zhou, J.; Ho, J.C.; Wong, C.Y. Developing controllable anisotropic wet etching to achieve silicon nanorods, nanopencils and nanocones for efficient photon trapping. J. Mater. Chem. A 2013, 1, 9942-9946. [CrossRef]

59. Yeom, J.; Ratchford, D.; Field, C.R.; Brintlinger, T.H.; Pehrsson, P.E. Decoupling Diameter and Pitch in Silicon Nanowire Arrays Made by Metal-Assisted Chemical Etching. Adv. Funct. Mater. 2014, 24, 106-116. [CrossRef]

60. Kim, J.; Han, H.; Kim, Y.H.; Choi, S.H.; Kim, J.C.; Lee, W. Au/Ag bilayered metal mesh as a Si etching catalyst for controlled fabrication of Si nanowires. ACS Nano 2011, 5, 3222-3229. [CrossRef] [PubMed]

61. Liebovitch, L.S.; Scheurle, D. Two lessons from fractals and chaos. Complexity 2000, 5, 34-43. [CrossRef]

62. Mandelbrot, B.B. A Fractal's Lacunarity, and how it can be Tuned and Measured. In Fractals in Biology and Medicine; Birkhäuser: Basel, Switzerland, 1994; pp. 8-21.

63. Plotnick, R.E.; Gardner, R.H.; Hargrove, W.W.; Prestegaard, K.; Perlmutter, M. Lacunarity analysis: A general technique for the analysis of spatial patterns. Phys. Rev. E 1996, 53, 5461-5468. [CrossRef] 
64. Lo Faro, M.J.; Ruello, G.; Leonardi, A.A.; Morganti, D.; Irrera, A.; Priolo, F.; Gigan, S.; Volpe, G.; Fazio, B. Visualization of Directional Beaming of Weakly Localized Raman from a Random Network of Silicon Nanowires. Adv. Sci. 2021, 8, 2100139. [CrossRef] [PubMed]

65. Fazio, B.; Irrera, A.; Pirotta, S.; D’Andrea, C.; Del Sorbo, S.; Lo Faro, M.J.; Gucciardi, P.G.; Iatì, M.A.; Saija, R.; Patrini, M.; et al. Coherent backscattering of Raman light. Nat. Photonics 2017, 11, 170-176. [CrossRef]

66. Lo Savio, R.L.; Miritello, M.; Cardile, P.; Priolo, F. Concentration dependence of the $\mathrm{Er}^{3+}$ visible and infrared luminescence in $\mathrm{Y}_{2-x} \mathrm{Er}_{\mathrm{x}} \mathrm{O}_{3}$ thin films on Si. J. Appl. Phys. 2009, 106, 043512. [CrossRef] 